\title{
Assessment and Validation of i-Skyradiometer Retrievals Using Broadband Flux and MODIS Data
}

\author{
S. Dipu, ${ }^{1,2}$ G. Pandithurai, ${ }^{1}$ A. S. Panicker, ${ }^{1}$ T. Takamura, ${ }^{3}$ \\ Dong-In Lee, ${ }^{4}$ and Dongchul $\mathrm{Kim}^{5}$ \\ ${ }^{1}$ Indian Institute of Tropical Meteorology, Pune 411008, India \\ ${ }^{2}$ Leipzig Institute for Meteorology, 04103 Leipzig, Germany \\ ${ }^{3}$ CEReS, Chiba University, Inage-ku, Chiba 263-8522, Japan \\ ${ }^{4}$ Department of Environmental Atmospheric Sciences, Pukyong National University, Busan 608737, Republic of Korea \\ ${ }^{5}$ Universities Space Research Association, Columbia, MD 21044, USA \\ Correspondence should be addressed to S. Dipu; dipuss@gmail.com and Dong-In Lee; leedi@pknu.ac.kr
}

Received 25 November 2013; Accepted 3 January 2014; Published 17 February 2014

Academic Editor: Sachin D. Ghude

Copyright (c) 2014 S. Dipu et al. This is an open access article distributed under the Creative Commons Attribution License, which permits unrestricted use, distribution, and reproduction in any medium, provided the original work is properly cited.

\begin{abstract}
Ground-based network of cloud measurements is presently limited and there exists uncertainty in the cloud microphysical parameters derived from ground-based measurements. Bias in the i-skyradiometer derived cloud optical depth $\left(\tau_{c}\right)$ and droplet effective radius $\left(R_{\mathrm{eff}}\right)$ and the importance of these parameters in the parameterization of clouds in climate models have made us intend to develop a possible method for improving these parameters. A new combination method, which uses zenith sky transmittance and surface radiation measurements, has been proposed in the present study to improve the retrievals. The iskyradiometer derived parameters $\tau_{c}$ and $R_{\text {eff }}$ have been provided as a first guess to a radiative transfer model (SBDART) and a new retrieval algorithm has been implemented to obtain the best combination of $\tau_{c}$ and $R_{\text {eff }}$ having minimum bias $(-0.09$ and -2.5 ) between the simulated global and diffuse fluxes at the surface with the collocated surface radiation measurements. The new retrieval method has improved $\tau_{c}$ and $R_{\text {eff }}$ values compared to those derived using the transmittance only method and are in good agreement with the MODIS satellite retrievals. The study therefore suggests a possible improvement of the i-skyradiometer derived cloud parameters using observed radiation fluxes and a radiative transfer model.
\end{abstract}

\section{Introduction}

The main challenges in numerical weather prediction using general circulation models are the representation of clouds and cloud related small-scale processes. Out of many cloud microphysical parameters, cloud optical depth $\left(\tau_{c}\right)$ and cloud droplet effective radius $\left(R_{\text {eff }}\right)$ are the key parameters, which determine the radiative properties of clouds such as reflection, transmission, and absorption of solar radiation [1]. The effects of the cloud related subgrid scale processes are mainly parameterized in terms of these bulk model variables, $R_{\text {eff }}$ and $\tau_{c}$. However, the climate models poorly simulate these variables $[2,3]$, but a better representation of $R_{\text {eff }}$ is essential to parameterize cloud microphysical process in numerical weather prediction and climate models $[4,5]$.
Sparse observations of cloud microphysical parameters using both ground-based instruments and remote sensing methods make it more difficult to improve the model simulations of these parameters. Even though satellite retrievals provide cloud microphysical properties globally, its coarse spatial and temporal resolution makes it insufficient to study the cloud microphysical properties in detail. Hence, accurate groundbased measurements of the cloud microphysical parameters on both local and global scales are important for validation of satellite retrievals, aerosol indirect effect estimates, and also for the improvement of model predictions [6].

Several methods have been used to retrieve cloud optical properties using ground-based and aircraft measurements. [7] derived $\tau_{c}$ from aircraft mounted solar radiometric measurements. The main drawback of this method 
includes limited temporal coverage and increased expense. Retrievals of cloud optical depth and effective cloud fraction using ground-based measurements of zenith radiance have been reported by [8]. Total liquid water path measured by microwave radiometer has also been used to obtain the $R_{\text {eff }}$ and this retrieval was applied to ARM (atmospheric radiation measurement) data to derive $\tau_{c}$ [9]. Recently, [10] reported that the $\tau_{c}$ retrieved from AERONET (AErosol RObotic NETwork) zenith radiance observations at 440 and $870 \mathrm{~nm}$ compared well with ARM MFRSR (multifilter rotating shadowband radiometer) observations.

The i-skyradiometer (POM-02) used in SKYNET is a unique instrument that can measure zenith transmittances at 1.6 and $2.2 \mu \mathrm{m}$ wavelengths similar to those of MODIS (moderate resolution imaging spectroradiometer) and can derive $\tau_{c}$ and $R_{\text {eff }}$ simultaneously. [11] compared $R_{\text {eff }}$ retrieved from the i-skyradiometer channels 1.6 and $2.2 \mu \mathrm{m}$ with $R_{\text {eff }}$ retrieved from radar reflectivity alone, radar reflectivity constrained with microwave radiometer (MWR) column liquid water path (LWP), and MODIS satellite and reported a bias in the POM-02 retrievals of $R_{\text {eff }}$ compared to the cloud radar and MODIS retrievals. Their study points towards the need for improvement of $\tau_{c}$ and $R_{\text {eff }}$ derived from i-skyradiometer. The present study is therefore aimed at providing a new method to improve the retrievals of $\tau_{c}$ and $R_{\text {eff }}$ from i-skyradiometer (POM-02) using a radiative transfer model in conjunction with collocated ground-based measurements of global and diffuse shortwave fluxes.

\section{Data and Instrumentation}

Observations of zenith sky transmittance and global and diffuse short-wave radiative fluxes carried out over two stations, (i) Chiba $\left(35.7^{\circ} \mathrm{N}, 139.7^{\circ} \mathrm{E}\right)$, an urban site in Japan, and (ii) Cape Hedo $\left(26.87^{\circ} \mathrm{N}, 128.25^{\circ} \mathrm{E}\right)$, a marine environment as part of the SKYNET (http://atmos.cr.chiba-u.ac.jp/) programme, [12] have been used in the present study. The study also utilizes measurements of cloud base and top heights and transmittance measurements. In this study, nonprecipitating water clouds with base below $2 \mathrm{~km}$ have been considered. For Chiba station, observations, during 4 days in April, May, and July of 2007 and, in Cape Hedo, 10 days during February, March, and April of 2008, have been considered for the analysis.

Shortwave pyranometer (made by Kipp and Zonen (model CM21)) has been used to measure global radiation over Chiba. It measures the global radiation in the spectral range 0.3 to $3.0 \mu \mathrm{m}$ on a plane surface, which results from the direct and diffuse solar radiation incident from the hemisphere above, with a spectral sensitivity of 7 to 14 $\mu \mathrm{V} / \mathrm{W} / \mathrm{m}^{2}$. Since the diffuse radiation was not available over Chiba during the analysis period, global solar radiation measurements were used in the study. A shaded Pyranometer (made by Kipp and Zonen (model CM21)) under a shading ball is used to measure the diffused radiation over Cape Hedo. Cloud base and cloud top heights were derived from frequency modulated continuous millimeter wave cloud radar (FMCW); a threshold radar reflectivity of $-15 \mathrm{dBZ}$ was used for selection of nonprecipitating clouds. Detailed technical description of FMCW radar and its comparison with a monostatic $95 \mathrm{GHz}$ cloud radar SPIDER can be obtained from [13].

$\tau_{c}$ and $R_{\text {eff }}$ were retrieved from the ground-based measurements of the transmitted solar radiation using Sun/Sky scanning radiometer called i-skyradiometer (POM-02). The POM Sun/Sky radiometer is manufactured by Prede Co., Ltd., Tokyo, which comes under the Asia-Pacific SKYNET network for aerosol monitoring and satellite ground-truth around the world. It has a narrow field of view $\left(1.2^{\circ}\right)$ that makes measurements in several narrow spectral bands in the ultraviolet visible and near-infrared parts of the spectrum. POM includes a dedicated sun tracker, which can follow the sun for direct radiation measurements and can also make programmed scans across the sky at defined angles away from the sun. There exist two versions of the POM sky radiometer, POM-01 and POM-02. The POM-01 sky radiometer uses a single detector and a rotating filter wheel to measure radiation in seven narrow bands from $0.315 \mu \mathrm{m}$ to $1.020 \mu \mathrm{m}$ $(0.315,0.4,0.5,0.675,0.87,0.940$, and $1.02 \mu \mathrm{m})$. It is connected to a computer running the operating software in order to make measurements and store data. The POM-02 has all the features of the POM-01, but with an extended wavelength range and has a second optical system with an indium gallium arsenide infrared detector. The filter has 11 wavebands, such that it can measure sky radiance and transmittance at 1.02, 1.6 , and $2.2 \mu \mathrm{m}$. For simultaneous determination of $\tau_{c}$ and $R_{\mathrm{eff}}$ from transmittance measurements, it is necessary to adopt both absorbing and nonabsorbing wavelength. At waterabsorbing wavelength, water droplet absorbs more solar radiation as particle increases in size compared to nonabsorbing wavelength, which absorbs less solar radiation. Among the three near-infrared wavelengths $(1.02,1.6$ and $2.2 \mu \mathrm{m})$, $1.02 \mu \mathrm{m}$ has been adopted as nonabsorbing wavelength, while the other two are water-absorbing wavelengths. Zenith sky cloud transmittance measurements at $1.02,1.6$ and $2.2 \mu \mathrm{m}$ were used to derive $\tau_{c}$ and $R_{\text {eff }}$ [1]. The retrieval procedure compares measurements of the cloud transmittance from the ground at water-absorbing and nonabsorbing wavelengths with look-up tables of the transmittance precomputed for plane-parallel, vertically homogeneous clouds using a radiative transfer code $r$-star4b [14]. Details of the retrieval algorithm are available in [1].

The i-skyradiometer is a radiance-based instrument, which works best for overcast conditions; hence overcast cases are considered in the study. The accurate determination of sky condition is desirable for identifying cloud type and cloud coverage. The whole sky imager (WSI) is a groundbased system, which enables temporal and spatial highresolution sky observations. It provides real time processing and display of daytime sky conditions using common image processing algorithm, which estimate the cloud cover fraction. The WSI consists of a web camera, which looks down at a slowly rotating mirror that has a black strip to occlude the direct solar irradiance from the camera. The images of the sky are collected by a local computer and processed into percent cloud cover data. The digital image analysis was based on red to blue ratio, which is used to distinguish between 


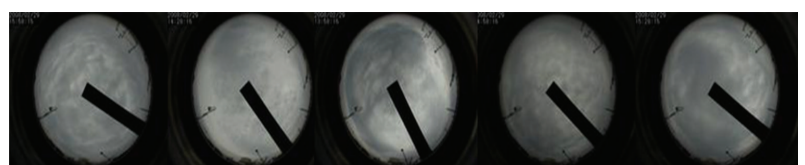

Figure 1: Whole sky images for April 4, 2008, over Cape Hedo, Japan.

clear and cloud pixels [15]. WSI data captured at every 10 minutes were used for selecting cloud cases. Figure 1 shows an example of cloud cases selected for April 4, 2008 at Cape Hedo, Japan. Further, satellite measurements are the only means of getting the global coverage of $\tau_{c}$ and $R_{\text {eff }}$. Hence, a comparison of the improved retrieval has been carried out with MODIS (Terra) level 2 products, with a spatial resolution of $1 \mathrm{~km}$ (MOD06). The swath data is averaged over an area of $4 \mathrm{~km}$ with experimental site as center and is compared with the improved retrieval.

\section{Methodology}

An assessment of the retrieval of cloud microphysical parameters from POM-02 and a new retrieval procedure has been proposed for improving the retrievals of $\tau_{c}$ and $R_{\mathrm{eff}}$ in conjunction with ground-based radiation measurements. A radiative transfer model, Santa Barbara discrete-ordinate atmospheric radiative transfer code (SBDART) [16], which simulates global and diffuse solar radiative fluxes at the surface and the collocated surface radiation measurements, has been used in the study [17-19]. A detailed description of SBDART uncertainty is available in [20-22]. The cloud optical parameters, $\tau_{c}$ and $R_{\text {eff }}$ retrieved from i-skyradiometer were assumed as a first guess (retrieval from skyradiometer) for the SBDART model. In addition, cloud base and top heights derived from a Frequency modulated continuous wave millimeter wave cloud radar (MMCR), MODIS column integrated water vapor, TOMS ozone, and climatological values of green house gasses such as $\mathrm{CO}_{2}, \mathrm{CH}_{4}$, and $\mathrm{N}_{2} \mathrm{O}$ were also constrained as inputs to the model [16]. Integrated water vapor is an important constituent of the atmosphere, which has high absorptivity of solar radiation. Its effect on aerosol optical depth and surface irradiance should be considered if the data from different months are mixed together [23]. Due to the complexity in the distribution of green house gases across the globe and the lack of availability of these parameters, we used default values, which is independent of season and geographic location.

Global and diffuse fluxes simulated by SBDART model (global fluxes over Chiba and diffuse fluxes over Cape Hedo) are compared with observed fluxes for different combinations of $\tau_{c}$ and $R_{\text {eff }}$. The new retrieval algorithm has been introduced for obtaining different combinations of the cloud microphysical parameters. Considering the fact that there is an underestimation in $R_{\text {eff }}$, the initial value of $R_{\text {eff }}$ has been incremented up to $8 \mu \mathrm{m}$ at an interval of $1 \mu \mathrm{m}$. Several studies have reported a threshold value of $R_{\text {eff }}$ less than $12 \mu \mathrm{m}$ for nonprecipitating clouds [24]. Since only nonprecipitating clouds have been considered in the study, $R_{\text {eff }}$ greater than

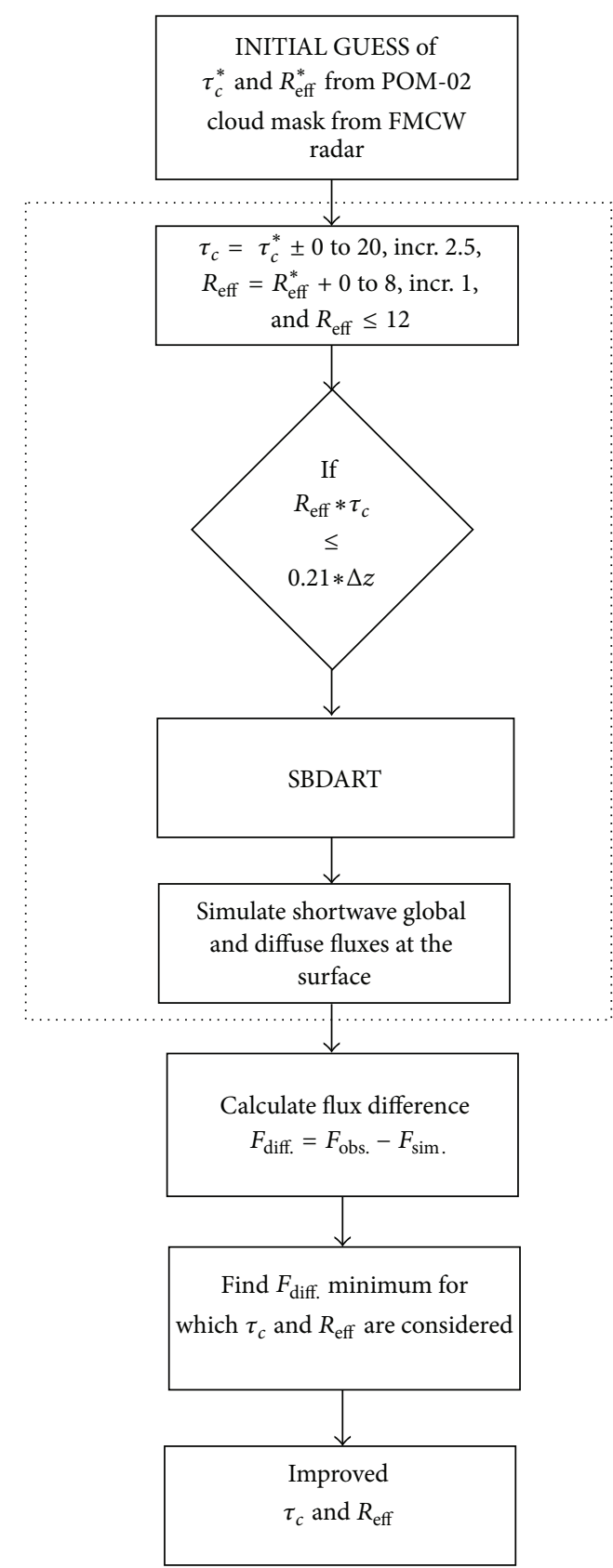

FIGURE 2: Flow chart of new retrieval algorithm for improved $\tau_{c}$ and $R_{\text {eff }}$.

$12 \mu \mathrm{m}$ is ignored during each step procedure [25]. The $R_{\text {eff }}$ computation was performed only in forward direction as the $R_{\text {eff }}$ values obtained from POM-02 (initial guess) were mostly found to be in the lower range; also the lower limit for $R_{\text {eff }}$ in SBDART model is $2 \mu \mathrm{m}$. However, forward and backward step have been performed for $\tau_{c}$ up to 20 at an interval of 2.5. Earlier studies reveal that $R_{\text {eff }}$ and $\tau_{c}$ are related through the equation $\tau_{c}=1.5 * \mathrm{LWP} / \rho_{l} * R_{\text {eff }}$ [26], where $\rho_{l}$ is density of liquid water and LWC can be obtained through the equation LWP $=0.14 * \Delta z$ [27], where $\Delta \mathrm{z}$ is cloud depth. Hence, $R_{\text {eff }}$ and $\tau_{c}$ computed after each step are checked for whether 


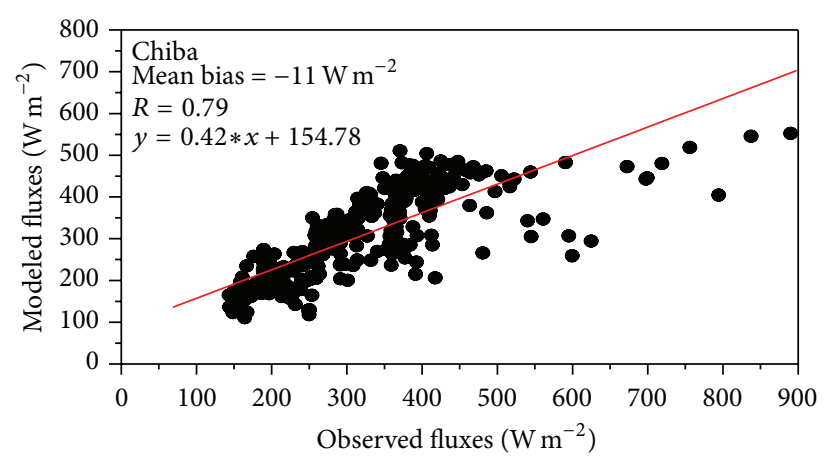

(a)

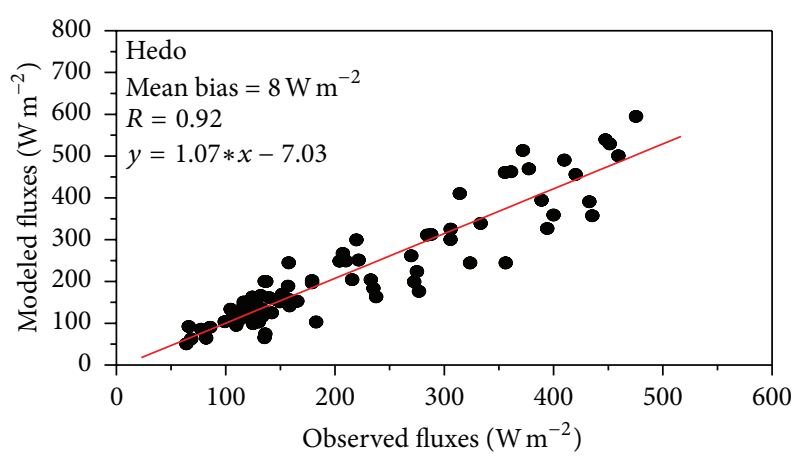

(b)

Figure 3: Comparison of observed and model simulated fluxes using initial guess of $\tau_{c}$ and $R_{\text {eff }}$ over (a) Chiba (global fluxes) and (b) Hedo (diffuse fluxes).

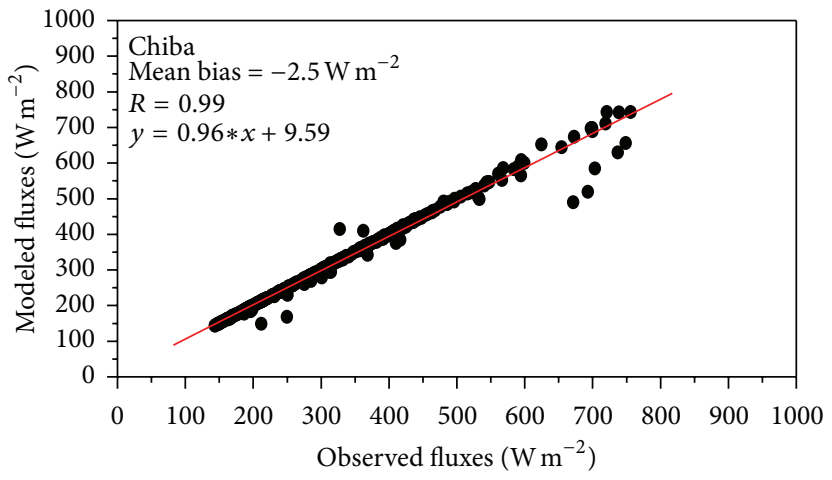

(a)

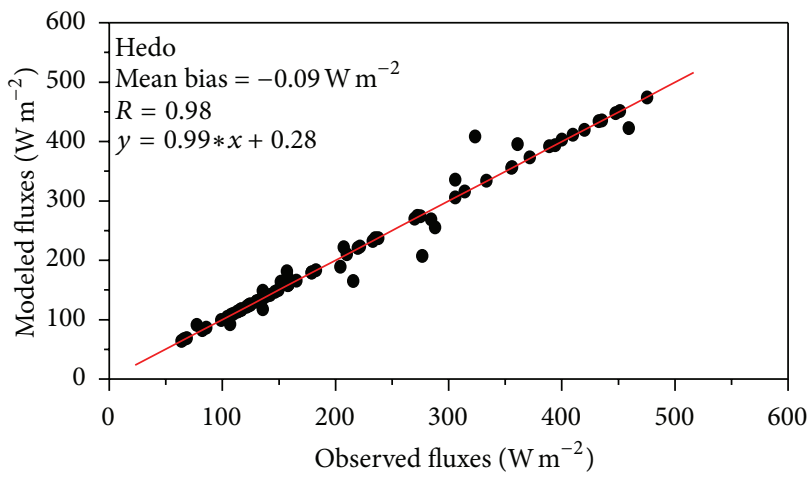

(b)

Figure 4: Comparison of observed and model simulated fluxes using the best combinations of $\tau_{c}$ and $R_{\text {eff }}$ over (a) Chiba (global fluxes) and (b) Hedo (diffuse fluxes).

the parameters hold the relationship, $\tau_{c} * R_{\text {eff }} \leq 0.21 * \Delta z$, obtained from the above equations provided by [26, 27]. After each iteration, SBDART simulated short-wave global and diffuse sky fluxes at the surface using different combinations of $\tau_{c}$ and $R_{\text {eff }}$ that are compared with the observed fluxes and the best combination of $\tau_{c}$ and $R_{\text {eff }}$, which simulates the fluxes having the least bias with observations, were selected as the most accurate retrievals. A flow chart illustrating the new retrieval procedure using the radiative transfer model, SBDART, is shown in Figure 2.

\section{Results and Discussions}

Initial retrievals of $\tau_{c}$ and $R_{\text {eff }}$ from i-skyradiometer using [1] have been used as first guess in SBDART to simulate shortwave fluxes (diffuse and global) at the surface and the comparison of SBDART simulated global (over Chiba) and diffuse fluxes (over Cape Hedo) with that of observation is presented in Figure 3. It can be noted from the figure that there is large difference between the observed and model derived initial fluxes (from initial guess values) over both regions. The mean bias in the model simulated fluxes was found to be $-11 \mathrm{Wm}^{-2}$ over Chiba and $8 \mathrm{Wm}^{-2}$ over Cape Hedo while the correlation coefficients between the observed and model simulated initial fluxes were obtained as 0.79 and 0.92 over Chiba and Cape Hedo, respectively. The large bias indicates that there is an uncertainty in retrieved products of $\tau_{c}$ and $R_{\text {eff }}$.

In the improved retrieval algorithm, the i-skyradiometer derived cloud optical properties $\left(\tau_{c}\right.$ and $\left.R_{\text {eff }}\right)$ were used as the first guess for SBDART model (Figure 2) and the combination of $\tau_{c}$ and $R_{\text {eff }}$ having the least bias in simulated fluxes has been estimated as the best combination. The fluxes simulated by the radiative transfer model using the best estimates of $\tau_{c}$ and $R_{\text {eff }}$ over Chiba and Cape Hedo have shown good agreement with observation (Figure 4). The improved retrieval algorithm has made a reduction in mean bias of simulated flux over Chiba from -11 to $-2.5 \mathrm{Wm}^{-2}$ (global) and also over Cape Hedo from $8 \mathrm{Wm}^{-2}$ to $-0.09 \mathrm{Wm}^{-2}$ (diffuse). The correlation coefficients between the improved and observed fluxes have been increased to 0.99 and 0.98 over Chiba and Cape Hedo, respectively. The best estimated values of $\tau_{c}$ and $R_{\text {eff }}$ from the new retrieval method were found to be improved as compared to those of the transmittance only retrievals obtained from POM-02. A better comparison of the improved retrievals of $\tau_{c}$ and $R_{\text {eff }}$ with that of initial retrievals can be obtained from Figures 5 and 6 . The $R_{\text {eff }}$ retrieval from transmittance method [1] is found to be lower as compared 


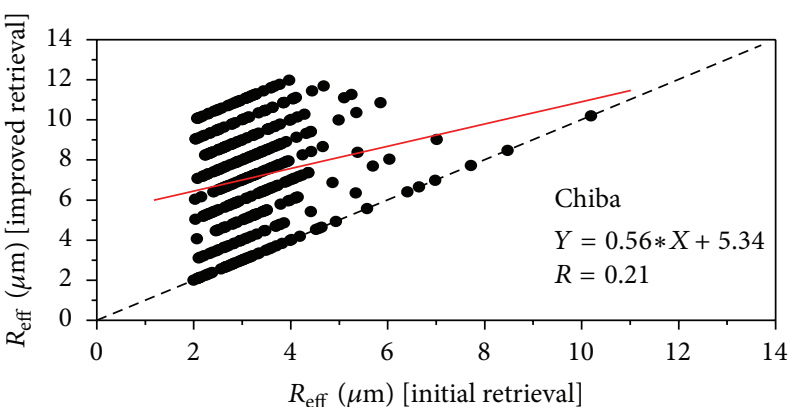

(a)

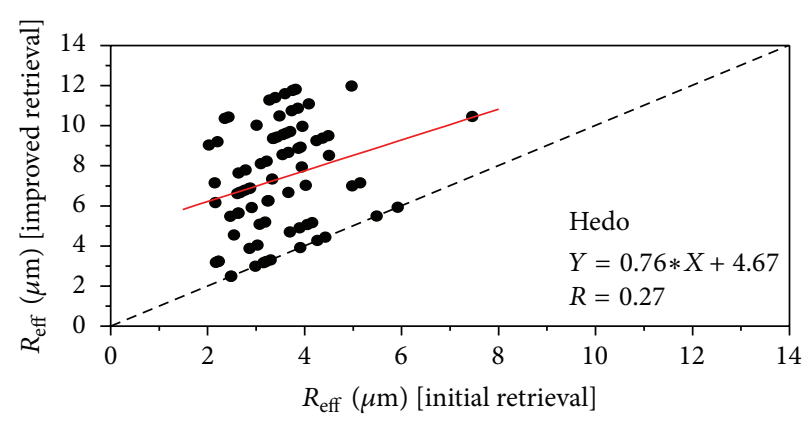

(b)

FIGURE 5: Initial and improved retrievals of cloud droplet effective radius over (a) Chiba and (b) Cape Hedo.

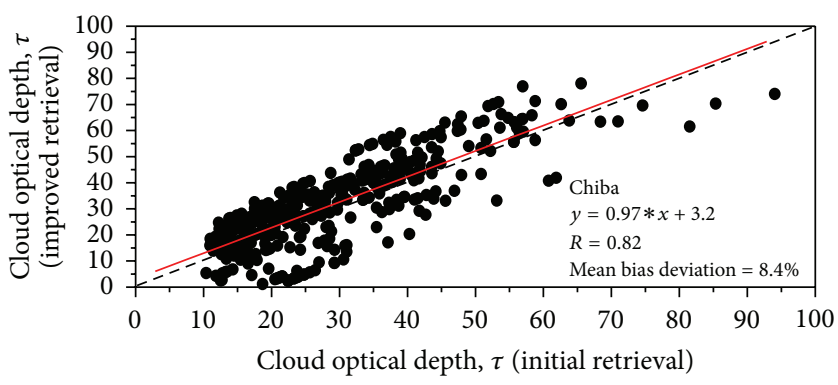

(a)

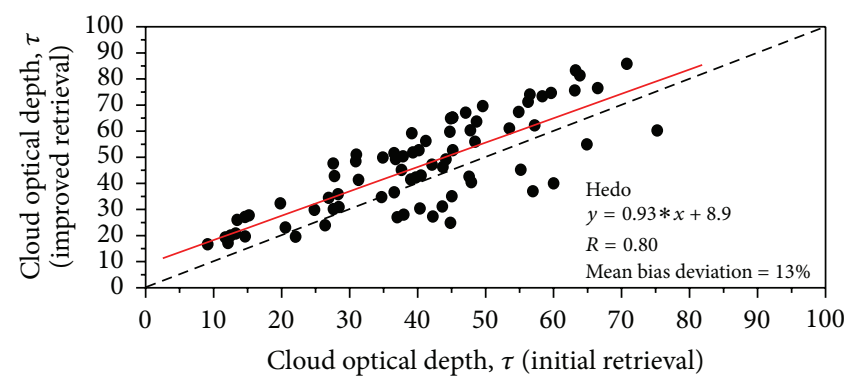

(b)

Figure 6: Initial and improved retrievals of cloud optical depth over (a) Chiba and (b) Cape Hedo.

to improved retrievals (Figure 5). The increase in improved retrievals of $R_{\text {eff }}$ is almost about double, which is in good agreement with radar and satellite retrievals reported by [11]. The improved retrievals for $\tau_{c}$ values have shown an increase of $8.4 \%$ over Cape Hedo and $13 \%$ over Chiba (Figure 6 ).

The retrievals of $R_{\text {eff }}$ and $\tau_{c}$ from both methods are compared with satellite retrievals and four cases (two from Chiba site (11 April and 18 May, 2007) and two from Cape Hedo site (28 February and 10 April, 2008)) are presented in Figures 7 and 8, respectively. The $R_{\text {eff }}$ derived using [1] method has shown values, between 2 and $4 \mu \mathrm{m}$, much lower than the MODIS derived $R_{\text {eff }}$, between 6 and $11 \mu \mathrm{m}$. The improved retrieval of $R_{\text {eff }}$ has shown considerable increase from the initial values [1] in all the cases over both stations, with a magnitude between 3 and $12 \mu \mathrm{m}$ (Figure 7 ). In all of the four days, the satellite had overpass during morning hours between 10:30 and 11:50 over the sites and improved retrievals have shown good agreement with the MODIS derived cloud effective radius during those hours. Comparison of the improved retrieval of $\tau_{c}$ has been carried out with the initial and satellite derived $\tau_{c}$ and is provided in Figure 8. In all of the four cases, the values of $\tau_{c}$ from improved retrieval method are found to be comparable with those derived from MODIS. Over Chiba station, the MODIS derived $\tau_{c}$ is found to be 20 on May 18. 2007. But the initial value derived by [1] method is much lower (14.5) and new retrieval technique has improved $\tau_{c}$ to 17.25 , more close to the MODIS derived value. However, on April 11, 2007, $\tau_{c}$ derived using the three methods was comparable, the MODIS observation and the $\tau_{c}$ derived using [1] method were in good agreement, and the improved algorithm has not made any considerable change in the initial value. The new retrieval method has improved $\tau_{c}$ over Cape Hedo station also. On April 10, 2008, the MODIS derived $\tau_{c}$ over Cape Hedo was 19 and the initial value was 10. The new retrieval method has made an increase in $\tau_{c}$ to 20, which is closer to MODIS observation. Even though the new retrieval method produced considerable improvements in $R_{\text {eff }}$ on February 28, 2008, the method could not improve $\tau_{c}$ considerably (Figure 8 ).

Further, sensitivity of the retrieved cloud microphysical parameters to the errors in observed fluxes used for improving the initial guess has also been carried out for understanding the robustness of the retrieved parameters. A sensitivity experiment has been conducted by introducing an error of $5 \%$ in the observed flux and found that it can induce an error of 2.5 units in the retrieved $\tau_{c}$ (with constant $R_{\text {eff }}$ ), whereas in $R_{\text {eff }}$ an error of $2.0 \mu \mathrm{m}$ can occur (with constant $\left.\tau_{c}\right)$. The error associated with the assumption of vertical inhomogeneity in the retrieval of $\tau_{c}$ using Kikuchi et al. [1] method is within $2 \%$ and it is argued that the cloud optical depth could be derived accurately from the measurements of transmittance [1]. Our analysis suggests that the POM-02 derived $\tau_{c}$ and $R_{\text {eff }}$ can be improved by utilizing collocated radiation measurements. The methodology proposed here for finding the best combination of $\tau_{c}$ and $R_{\text {eff }}$ using POM-02 retrievals as first guess and radiative fluxes as reference can 


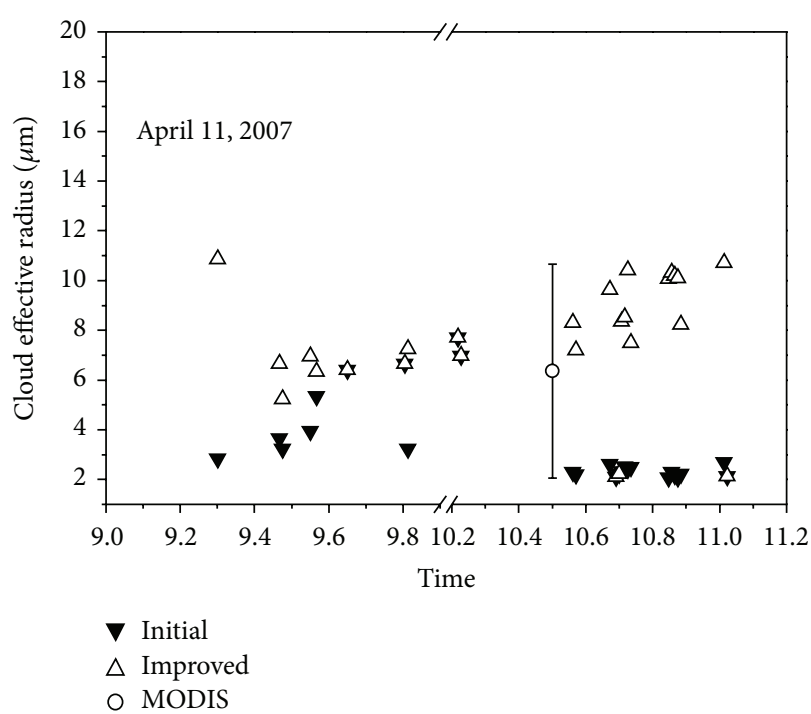

(a)

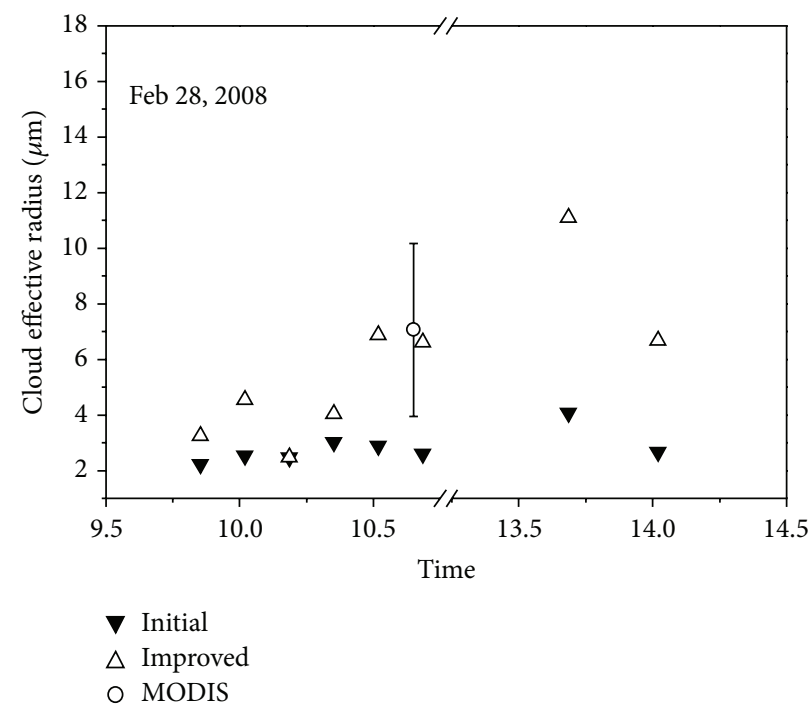

(c)

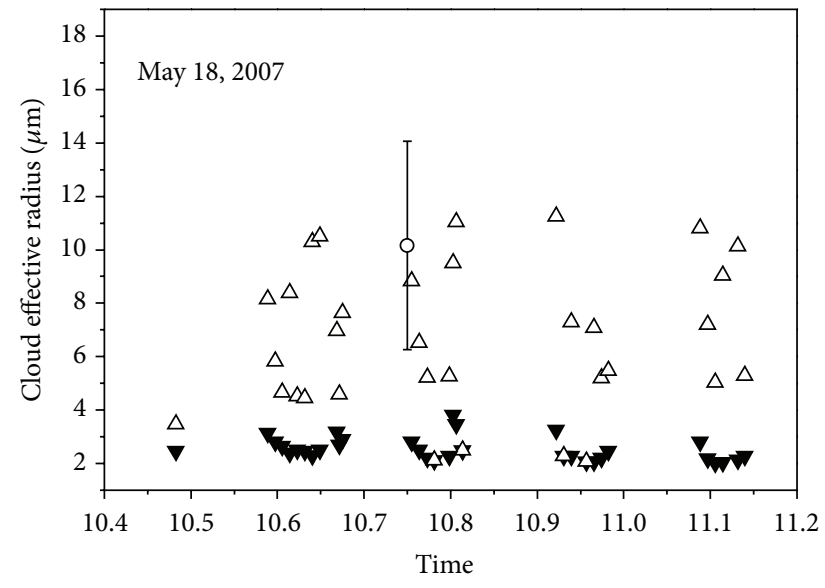

$\boldsymbol{\nabla}$ Initial

$\triangle$ Improved

o MODIS

(b)

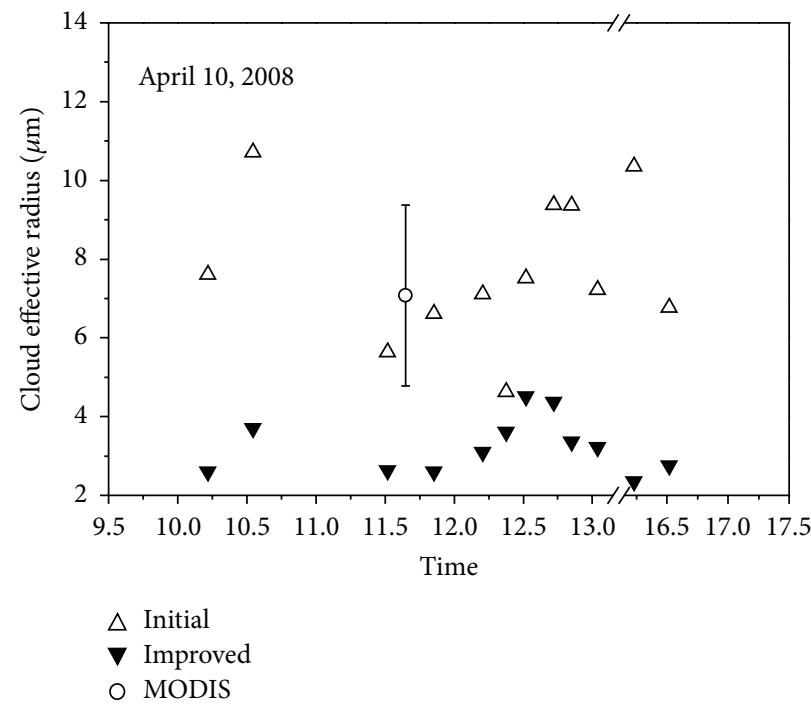

(d)

FIGURE 7: Initial, improved and satellite derived cloud droplet effective radius for Chiba (11 April and 18 May, 2007) and Cape Hedo (28 February and 10 April, 2008).

be used for improving the POM-02 retrievals, as accurate radiative flux observations are available in SKYNET sites.

\section{Summary}

Clouds remain the greatest source of uncertainty in global climate change research. Limited observations using groundbased instruments and the course resolution of satellite measurements add more uncertainty in the estimation and prediction of cloud microphysical parameters. Bias in the cloud parameters, $\tau_{c}$ and $R_{\text {eff }}$, derived using i-skyradiometer (a unique instrument that can measure zenith sky transmittances at 1.6 and $2.2 \mu \mathrm{m}$ wavelengths and can derive $\tau_{c}$ and $R_{\text {eff }}$ simultaneously) made it important to provide a technique for improving these parameters. A new combination method, which uses zenith sky transmittance and surface radiation (global and diffuse) measurements, has been proposed to improve the retrievals of $\tau_{c}$ and $R_{\text {eff. }}$ The method uses a radiative transfer model (SBDART) and the i-skyradiometer derived $\tau_{c}$ and $R_{\text {eff }}$ have been provided as first guess. Further, a new retrieval method has been implemented to obtain the best combination of $\tau_{c}$ and $R_{\text {eff }}$ having less bias between the simulated global and diffuse fluxes at the surface with the collocated surface radiation measurements.

The $\tau_{c}$ and $R_{\text {eff }}$ derived using the new retrieval method have shown considerable improvement compared to the parameters derived using [1] method and the instantaneous values are seen in good agreement with the MODIS satellite observations. The new retrieval of $R_{\text {eff }}$ has shown an increase in the magnitude of $R_{\text {eff }}$ with values between 3 and $12 \mu \mathrm{m}$, 


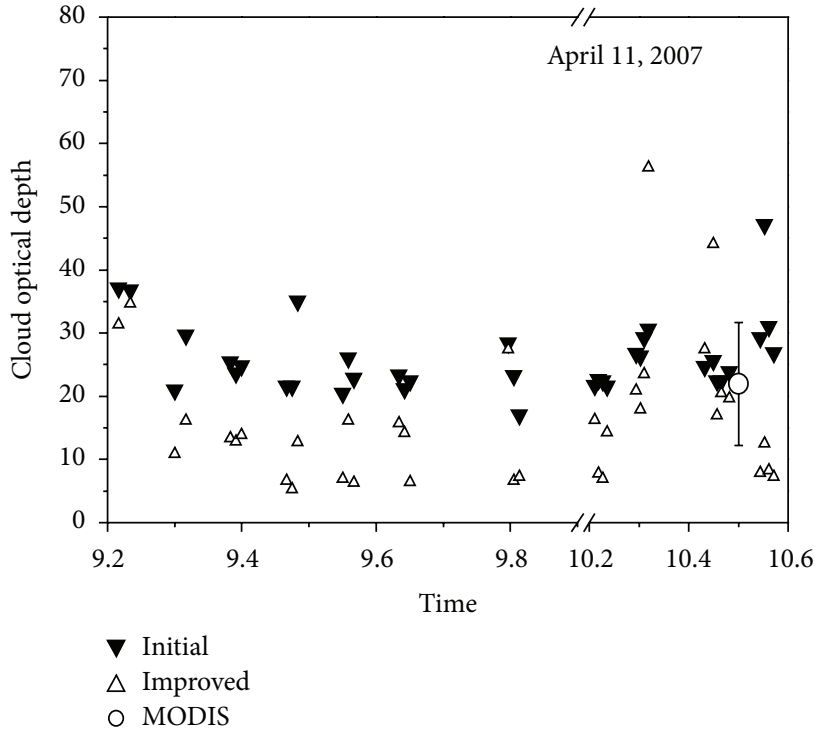

(a)

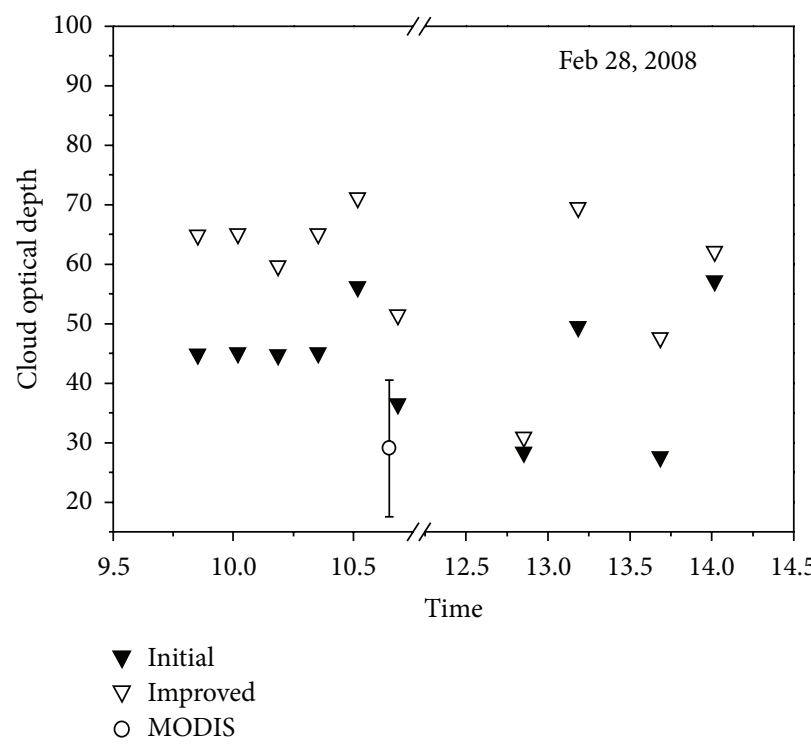

(c)

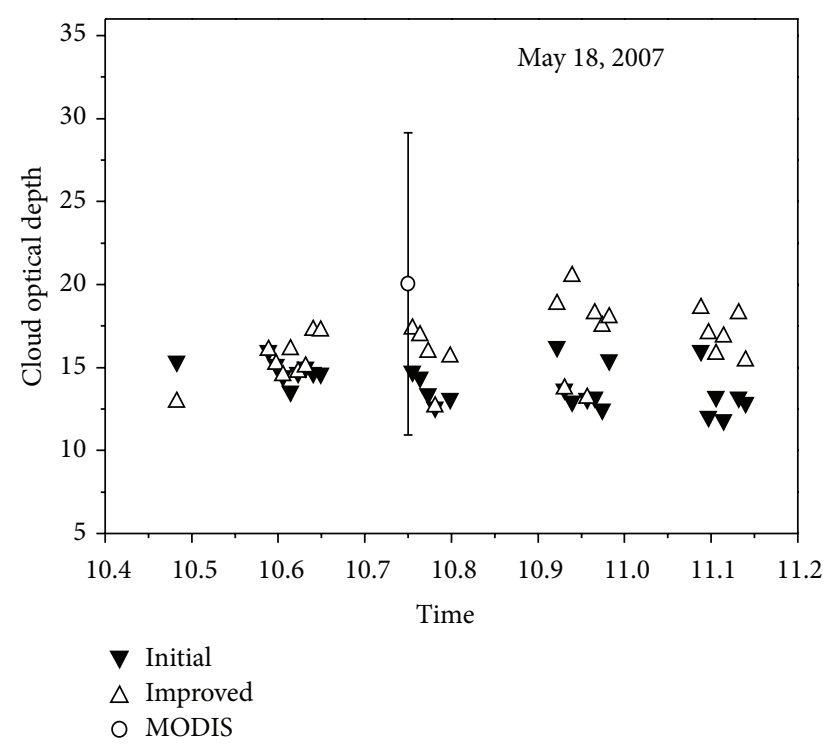

(b)

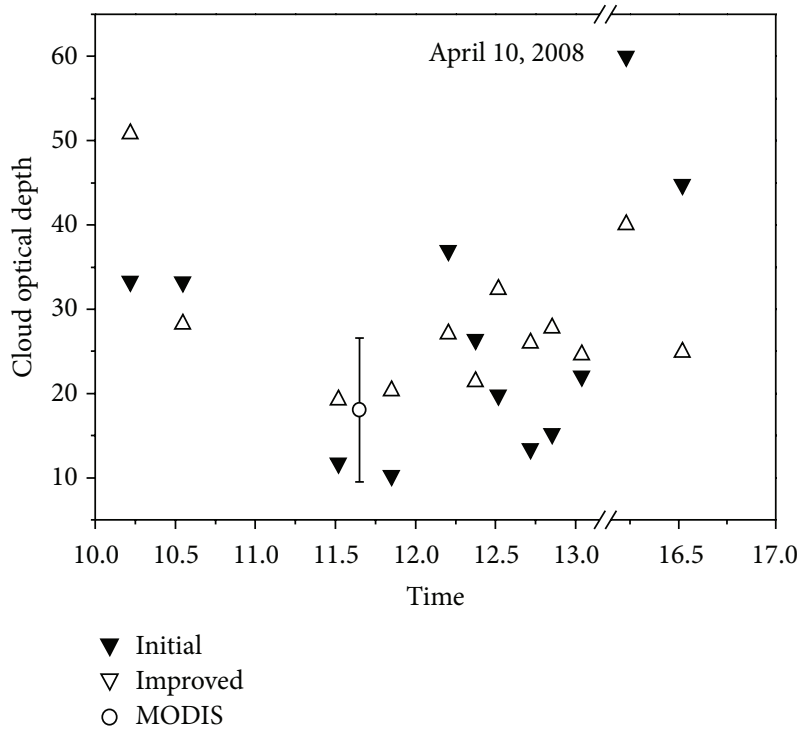

(d)

FIGURE 8: Initial, improved and satellite derived cloud optical depth for Chiba (11 April and 18 May, 2007) and cape Hedo (28 February and 10 April, 2008).

which is more closer to the MODIS derived $R_{\text {eff }}$ between 6 and $11 \mu \mathrm{m}$, while the $R_{\text {eff }}$ derived using [1] method is in the range of 2 to $4 \mu \mathrm{m}$. The MODIS satellite observed $\tau_{c}$ lies between 15 and 30 and the $\tau_{c}$ derived using the improved retrieval method has been found to be closer to MODIS observations compared to that obtained from [1] method. Our study therefore suggests that the POM-02 derived $\tau_{c}$ and $R_{\text {eff }}$ can be improved. The retrieval method suggests that POM-02 derived $\tau_{c}$ and $R_{\text {eff }}$ can be improved by utilizing the collocated radiation measurements. Indeed, this result may also used to improve the retrieval algorithm of skyradiometer for more robust cloud retrievals and hence, better retrievals of cloud parameters especially in SKYNET; an
Asian surface network for aerosol-radiation measurements can be achieved.

\section{Conflict of Interests}

The authors declare that there is no conflict of interests regarding the publication of this paper.

\section{Acknowledgments}

Indian Institute of Tropical Meteorology (IITM) and Centre for Climate Change Research (CCCR) are fully funded by Ministry of Earth Sciences (MoES), Government of India. 
The authors thank SKYNET and CHAMMPS and Cape Hedo for maintaining the experimental facilities at the site. The authors also thank Global Earth Observation System of Systems (GEOSS) and Ministry of Education, Culture, Sports, Science and Technology (MEXT), Japan. S. Dipu gratefully acknowledges CSIR, Government of India, for Research Fellowship. G. Pandithurai acknowledges the Japan Society for Promotion of Science (JSPS) for Invitation Fellowship. This work is supported by National Research Foundation of Korea (NRF) through a Grant provided by the Korean Ministry of Education, Science and Technology (MEST) 2013 (no. 200603874).

\section{References}

[1] N. Kikuchi, T. Nakajima, H. Kumagai et al., "Cloud optical thickness and effective particle radius derived from transmitted solar radiation measurements: comparison with cloud radar observations," Journal of Geophysical Research D, vol. 111, no. 7, Article ID D07205, 2006.

[2] M. H. Zhang, W. Y. Lin, S. A. Klein et al., "Comparing clouds and their seasonal variations in 10 atmospheric general circulation models with satellite measurements," Journal of Geophysical Research D, vol. 110, no. 15, Article ID D15S02, 2005.

[3] F. A. Bender, H. Rodhe, R. J. Charlson, A. M. L. Ekman, and N. Loeb, "22 views of the global albedo-comparison between 20 GCMs and two satellites," Tellus A, vol. 58, no. 3, pp. 320-330, 2006.

[4] G. L. Stephens, "Radiation profiles in extended water clouds. II parameterization schemes," Journal of the Atmospheric Sciences, vol. 35, no. 11, pp. 2123-2132, 1978.

[5] A. Slingo and H. M. Schrecker, "On the shortwave radiative properties of stratiform water clouds," Quarterly Journal, Royal Meteorological Society, vol. 108, no. 456, pp. 407-426, 1982.

[6] S. J. Evans and J. D. Haigh, "The retrieval of total optical depth and effective droplet radius of clouds from solar reflection measurements using the along track scanning radiometer-2 (ATSR-2)," Geophysical Research Letters, vol. 22, no. 6, pp. 695698, 1995.

[7] H. W. Barker, A. Marshak, W. Szyrmer, A. Trishchenko, J. Blanchet, and $\mathrm{Z}$. Li, "Inference of cloud optical depth from aircraft-based solar radiometric measurements," Journal of the Atmospheric Sciences, vol. 59, no. 13, pp. 2093-2111, 2002.

[8] J. C. Chiu, A. Marshak, Y. Knyazikhin et al., "Remote sensing of cloud properties using ground-based measurements of zenith radiance," Journal of Geophysical Research D, vol. 111, no. 16, Article ID D16201, 2006.

[9] Q. L. Min and L. C. Harrison, "Cloud properties derived from surface MFRSR measurements and comparison with GOES results at the ARM SGP site," Geophysical Research Letters, vol. 23, no. 13, pp. 1641-1644, 1996.

[10] J. C. Chiu, C. H. Huang, A. Marshak et al., "Cloud optical depth retrievals from the aerosol robotic network (AERONET) cloud mode observations," Journal of Geophysical Research D, vol. 115, no. 14, Article ID D14202, 2010.

[11] G. Pandithurai, T. Takamura, J. Yamaguchi et al., "Aerosol effect on cloud droplet size as monitored from surface-based remote sensing over East China Sea region," Geophysical Research Letters, vol. 36, no. 13, Article ID L13805, 2009.

[12] T. Takamura, N. Sugimoto, A. Shimizu et al., "Aerosol radiative characteristics at Gosan, Korea, during the atmospheric brown cloud East Asian regional experiment 2005," Journal of Geophysical Research D, vol. 112, no. 22, Article ID D22S36, 2007.

[13] T. Takano, K. Akita, H. Kubo et al., "Observations of clouds with the newly developed cloud profiling FM-CW radar at $95 \mathrm{GHz}$," in 10th Remote Sensing of Clouds and the Atmosphere, vol. 5979 of Proceedings of SPIE, Bruges, Belgium, September 2005.

[14] T. Nakajima and M. Tanaka, "Matrix formulations for the transfer of solar radiation in a plane-parallel scattering atmosphere," Journal of Quantitative Spectroscopy and Radiative Transfer, vol. 35, no. 1, pp. 13-21, 1986.

[15] G. Pfister, R. L. Mckenzie, J. B. Liley, A. Thomas, B. W. Forgan, and C. N. Long, "Cloud coverage based on all-sky imaging and its impact on surface solar irradiance," Journal of Applied Meteorology, vol. 42, no. 10, pp. 1421-1434, 2003.

[16] P. Ricchiazzi, S. Yang, C. Gautier, and D. Sowle, "SBDART: a research and teaching software tool for plane-parallel radiative transfer in the rarth's atmosphere," Bulletin of the American Meteorological Society, vol. 79, no. 10, pp. 2101-2114, 1998.

[17] W. C. Conant, "An observational approach for determining aerosol surface radiative forcing: results from the first field phase of INDOEX," Journal of Geophysical Research D, vol. 105, no. 12, pp. 15347-15360, 2000.

[18] G. Pandithurai, R. T. Pinker, T. Takamura, and P. C. S. Devara, "Aerosol radiative forcing over a tropical urban site in India," Geophysical Research Letters, vol. 31, no. 12, Article ID L12107, 2004.

[19] A. S. Panicker, G. Pandithurai, T. Takamura, and R. T. Pinker, "Aerosol effects in the UV-B spectral region over Pune, an urban site in India," Geophysical Research Letters, vol. 36, no. 10, Article ID L10802, 2009.

[20] A. S. Panicker, G. Pandithurai, P. D. Safai, and S. Kewat, "Observations of enhanced aerosol longwave radiative forcing over an urban environment," Geophysical Research Letters, vol. 35, no. 4, Article ID L04817, 2008.

[21] A. S. Panicker, G. Pandithurai, P. D. Safai, S. Dipu, and D. I. Lee, "On the contribution of black carbon to the composite aerosol radiative forcing over an urban environment," Atmospheric Environment, vol. 44, no. 25, pp. 3066-3070, 2010.

[22] A. S. Panickera, S.-H. Park, D.-I. Leeb et al., "Observations of black carbon characteristics and radiative forcing over a global atmosphere watch supersite in Korea," Atmospheric Environment, vol. 77, pp. 98-104, 2013.

[23] Z. Li and A. Trishchenko, "Quantifying the uncertainties in determining SW cloud radiative forcing and cloud absorption due to variability in atmospheric condition," Journal of the Atmospheric Sciences, vol. 58, no. 4, pp. 376-389, 2001.

[24] M. O. Andreae, D. Rosenfeld, P. Artaxo et al., "Smoking rain clouds over the Amazon," Science, vol. 303, no. 5662, pp. 13371342, 2004.

[25] D. Rosenfeld, "Suppression of rain and snow by urban and industrial air pollution," Science, vol. 287 , no. 5459, pp. $1793-$ 1796, 2000.

[26] D. D. Turner, A. M. Vogelmann, R. T. Austin et al., "Thin liquid water clouds: their importance and our challenge," Bulletin of the American Meteorological Society, vol. 88, no. 2, pp. 177-190, 2007.

[27] A. V. Korolev, G. A. Isaac, J. W. Strapp, S. G. Cober, and H. W. Barker, "In situ measurements of liquid water content profiles in midlatitude stratiform clouds," Quarterly Journal of the Royal Meteorological Society, vol. 133, no. 628, pp. 1693-1699, 2007. 

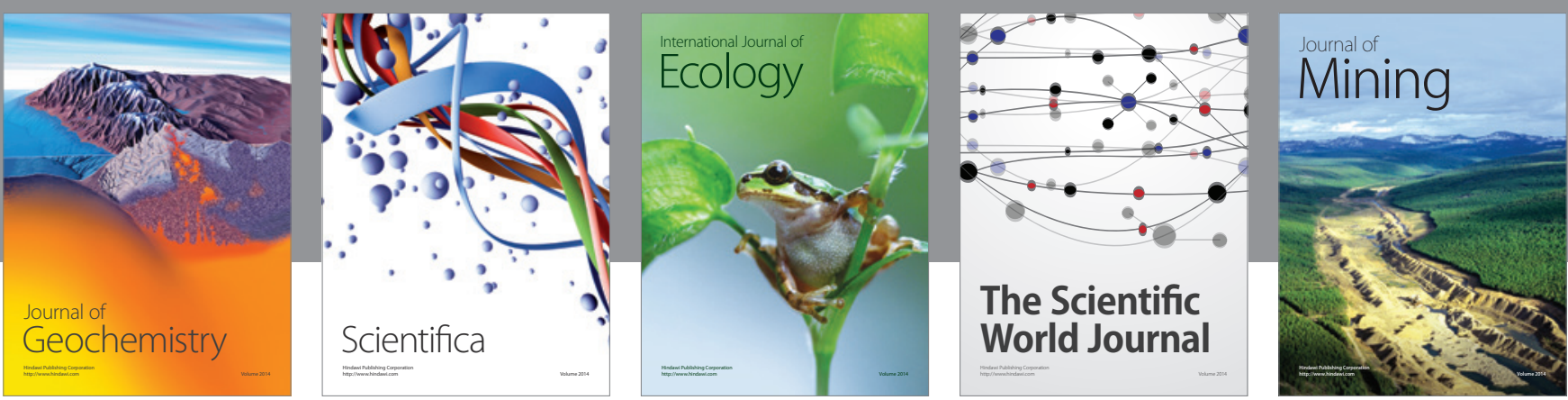

The Scientific World Journal
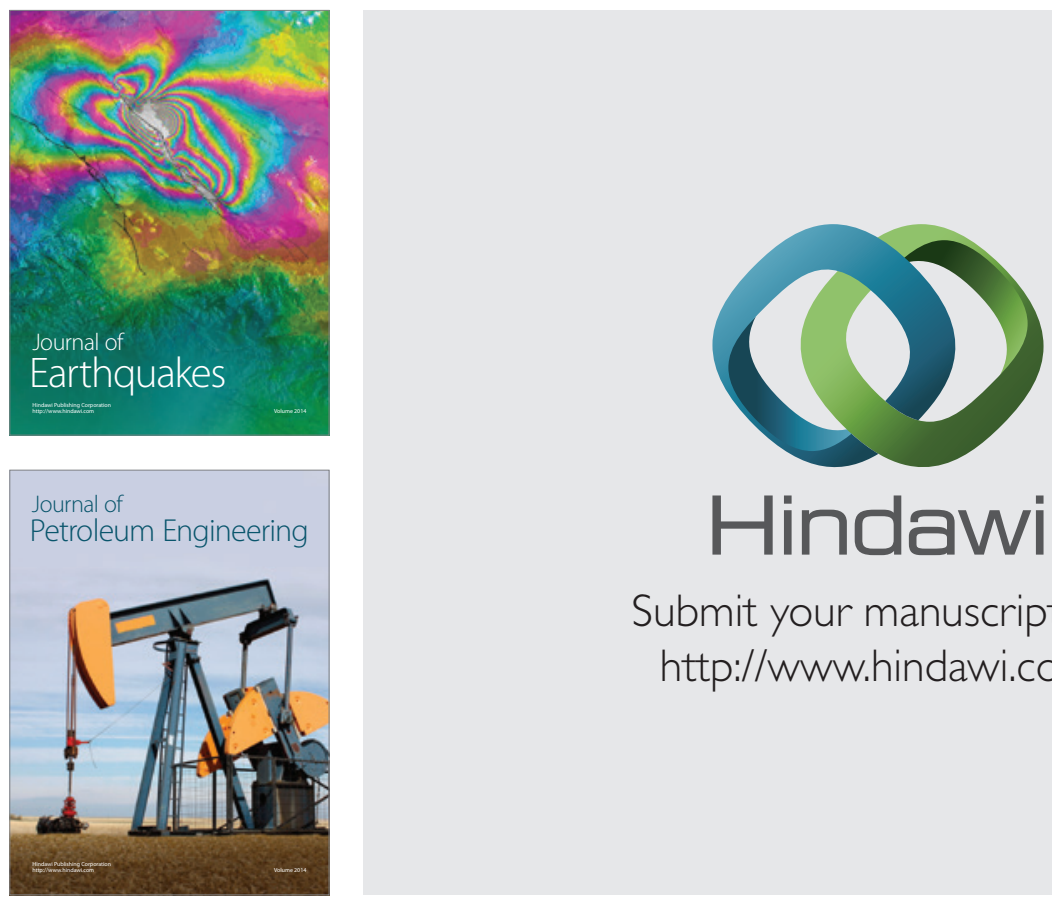

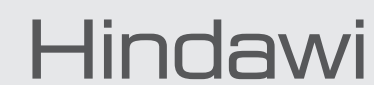

Submit your manuscripts at

http://www.hindawi.com
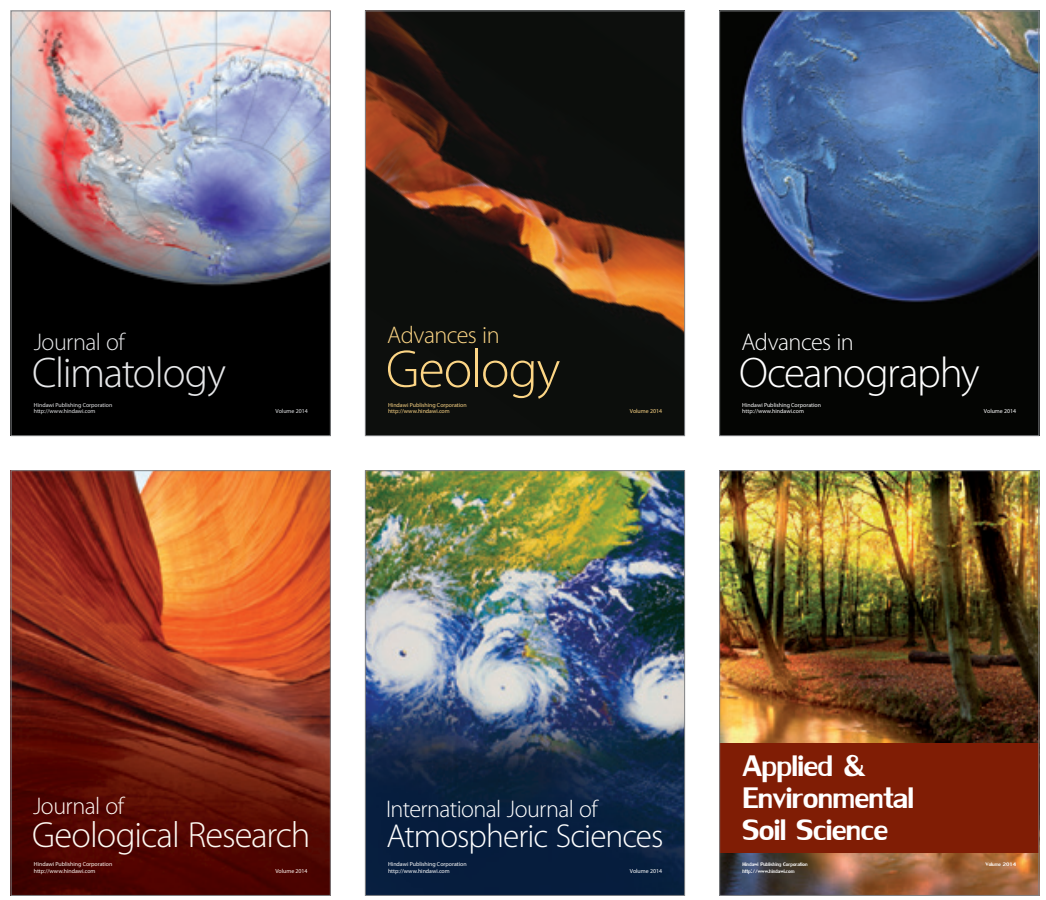
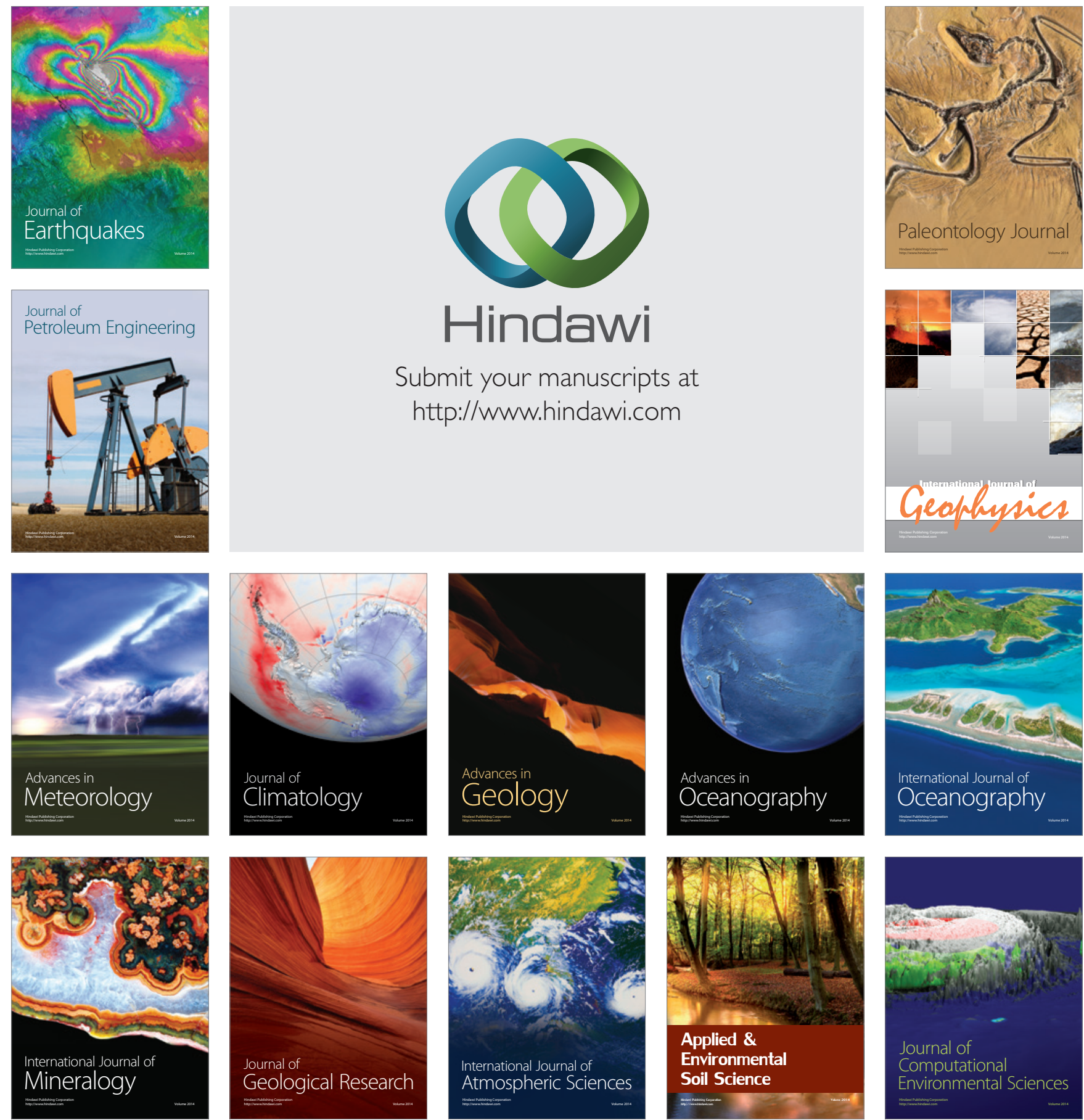